\title{
Improved Protocol for Transformation of Maize (Zea mays L.) Mediated by Agrobacterium tumefaciens
}

\author{
Yuji ISHIDA $^{1 *}$, Hideaki SAITO ${ }^{2}$, Yukoh HIEI ${ }^{1}$ and Toshihiko KOMARI ${ }^{1}$ \\ ${ }^{1}$ Plant Innovation Center, Japan Tobacco Inc, 700 Higashibara, Toyoda, Iwata, Shizuoka 438-0802, Japan \\ ${ }^{2}$ Applied Plant Research Center, Japan Tobacco Inc., 1900 Idei, Oyama, Tochigi 323-0808, Japan \\ *Corresponding author E-mail address: yuji.a.ishida@ims.jti.co.jp
}

Received 27 September 2002; accepted 9 November 2002

\begin{abstract}
Maize inbred H99 and A188 generally respond well in tissue culture, but only A188 had been efficiently transformed by Agrobacterium tumefaciens by the method previously described. The problem in transformation of $\mathrm{H} 99$ appeared to be a negative impact of infection with A. tumefaciens. Various conditions and additives to the culture media to promote callus induction from infected immature embryos were screened. Two major modifications, 1) addition of silver nitrate to the media for selection of transformed cells and 2) use of carbenicillin in place of cefotaxime to eliminate bacteria after infection, turned out to be most effective. A large number of transgenic plants of $\mathrm{H} 99$ were produced by the improved protocol based on these modifications, whereas no transformants were created by the original protocol in these genotypes. Integration and inheritance of the transgenes were confirmed by Southern hybridization and genetic analysis. Even the frequency of transformation of A188 was further improved by the new protocol.
\end{abstract}

Key words: $\mathrm{AgNO}_{3}$, Agrobacterium tumefaciens, carbenicillin, maize, transformation.

\begin{abstract}
Abbreviations
AOA, aminoxyacetic acid; AVG, aminoethoxyvinylglycine; GUS, $\beta$-glucuronidase; PPT, phosphinothricin; SOD, superoxide dismutase; STS, silver thiosulfate.
\end{abstract}

\section{Introduction}

The soil pathogen Agrobacterium tumefaciens can genetically transform plant cells with DNA segments (T-DNA) from a tumor-inducing plasmid (Ti plasmid) (Nester and Kosuge, 1981). Transformation systems that employ this naturally occurring machinery for the integration of foreign DNA into plant chromosomes were developed first in Solanaceae plants in the early 1980s (Horsch et al., 1985). Since then, high frequency transformation protocols in many dicotyledonous plants have been continuously reported and Agrobacterium-mediated gene transfer has been a standard method for transformation of these plants. It was considered in an earlier stage that this technology might not be extended to monocotyledonous plants, which are not the natural hosts for $A$. tumefaciens. However, a highly efficient method of transformation of rice by
A. tumefaciens was reported (Hiei et al., 1994), being followed by successful reports of transformation of important cereals such as maize (Ishida et al., 1996), wheat (Cheng et al., 1997), barley (Tingay et al, 1997) and sorghum (Zhao et al., 2000) by $A$. tumefaciens. Types of plant materials for infection with $A$. tumefaciens, choices of vectors and strains of $A$. tumefaciens, and optimization in tissue culture techniques have been among the key factors in these achievements.

Transgenic maize plants were first obtained by an electroporation method (Rhodes et al., 1988). Other direct gene transfer methods such as microprojectile bombardment (Fromm et al., 1990; Gordon-Kamm et al., 1990), tissue electroporation (D'Halluin et al., 1992) and the "whisker" method (Frame et al., 1994), have also been employed; microprojectile bombardment has been the most popular technique so far in maize transformation. Transgenic plants with high copy numbers of the foreign DNA, which are often rearranged extensively, are found in plants transformed by direct gene transfer methods much more frequently than those by $A$. tumefaciens, and the infection of maize with $A$. tumefaciens had been attempted by a number of laboratories since the mid 80 s. Graves and Goldman (1986) infected intact 
seedlings of maize and detected the expression of a foreign gene. Gould et al. (1991) obtained regenerated plants expressing a marker gene from shoot apices of maize that had been co-cultivated with $A$. tumefaciens. However, genetic and molecular evidence for stable transformation and transmission of the transgenes to the progeny provided in these reports was not conclusive. "Agro-infection", in which the cDNA of the maize streak virus was delivered to maize plants by $A$. tumefaciens with the resultant systemic infection of maize with the virus, was reported by Grimsley et al. (1987). This system provided evidence that DNA was transferred from A. tumefaciens to maize and elucidated various parameters affecting the transfer process, but stable integration of the T-DNA into the maize genome was not demonstrated in these studies.

Ishida et al. (1996) inoculated immature embryos of maize inbred A188 with A. tumefaciens and obtained transgenic maize plants from $5 \%$ to $30 \%$ of the embryos. The perceived advantages of Agrobacterium-mediated transformation methods, which include high efficiency and frequency of insertion of small numbers of copies of transgenes without many rearrangements, were also evident in maize. However, compared to the fact that Agrobacteriummediated gene transfer became wide spread in a very short time in rice, only a limited number of studies employing Agrobacterium-mediated transformation in maize have been reported since then (Deji et al., 2000; Negrotto et al., 2000; Nomura et al., 2000a,b; Taniguchi et al., 2000). This seems largely due to the fact that very limited genotypes, effectively only inbred A188, which is of little agronomic value, and hybrids related to $\mathrm{A} 188$, were transformable at a high frequency by the original protocol or the modified protocols, which were recently reported (Zhao et al., 2001; Frame et al., 2002).

We hereby report an improved protocol for the transformation of maize; other genotypes, $\mathrm{H} 99$ and W117, which were once elite inbreds widely used in the U. S. Corn Belt, were transformed at a reasonable frequency, and A188 was transformed at a frequency even higher than by the original protocol.

\section{Materials and Methods}

\section{Plant materials}

Public inbred lines of maize, A188, H99, W117 and W182E, were supplied from the National Institute of Agrobiological Resources of Japan. These inbreds are somewhat similar in their response to tissue culture; a compact embryogenic callus ("type I" callus) is readily induced (Hodges et al., 1986).
Especially, because the frequency of callus induction is very high in A188 and H99, these genotypes have been widely used as experimental materials in tissue culture (Songstad et al., 1988) and direct transformation (D'Halluin et al., 1992; Brettscuneider et al., 1997).

Plants were grown in a greenhouse, and ears were harvested between 9 and 16 days after pollination. Immature embryos of 1.0 to $1.2 \mathrm{~mm}$ or of 1.5 to 2.0 $\mathrm{mm}$ in length were aseptically excised and subjected to the experiments. Unless specifically mentioned, the immature embryos used in the experiments are those of 1.0 to $1.2 \mathrm{~mm}$ in length.

\section{Bacterial strains and plasmids}

A. tumefaciens strain LBA4404 (pSB131) was previously described (Ishida et al., 1996). The T DNA of pSB131 contained a phosphinothricin (PPT)-resistance gene (bar) and a gene for GUS, which has an intron in the $\mathrm{N}$-terminal region of the coding sequence and is connected to the $35 \mathrm{~S}$ promoter of cauliflower mosaic virus. This intron-gus gene expresses GUS activity in plant cells but not in the cells of A. tumefaciens (Ohta et al., 1990).

\section{Infection}

The method of inoculation and the composition of the media were according to the protocol previously described (Ishida et al., 1996). A. tumefaciens LBA4404 (pSB131) was cultivated on YP-medium that contained $50 \mathrm{mg} \mathrm{l}^{-1}$ spectinomycin at $28{ }^{\circ} \mathrm{C}$ for 3 to 4 days. The bacteria were collected and suspended at a density of $1 \times 10^{9} \mathrm{cfu} \mathrm{m}^{-1}$ in LS-inf medium (Ishida et al., 1996) that was supplemented with $100 \mu \mathrm{M}$ acetosyringone. The immature embryos were immersed into LS-inf medium and washed once with the same medium. The bacterial suspension was then added to the immature embryos in a tube, and the contents were stirred by a vortex mixer for $30 \mathrm{~s}$. After $5 \mathrm{~min}$, the immature embryos were plated on LS-AS cocultivation medium (Ishida $e t$ al., 1996) and incubated at $25^{\circ} \mathrm{C}$ in the dark for 3 days.

\section{Investigation of callus induction from inoculated immature embryos}

All the substances evaluated for their effects on callus induction were dissolved in distilled water, filter-sterilized, and then added to the autoclaved media. Inoculated immature embryos were transferred to the callus induction medium, LSD1.5, which contained $250 \mathrm{mg} \mathrm{l}^{-1}$ cefotaxime or carbenicillin and several concentrations of the substances (Table 1). Between 20 and 30 immature embryos were plated on each callus induction medium after 
co-cultivation, and each experiment was repeated three times. Plates were incubated at $25^{\circ} \mathrm{C}$ in the dark, and the numbers of immature embryos that induced type I calli were counted 2 weeks after incubation.

\section{Transformation}

Immature embryos of A188, H99 and W117 were inoculated and co-cultivated with LBA4404 (pSB131) and cultured on improved LSD1.5 medium (LSD1.5 medium containing $10 \mu \mathrm{M} \mathrm{AgNO}$ and $250 \mathrm{mg}^{-1}$ carbenicillin) supplemented with 5 $\mathrm{mg}^{-1}$ PPT for between 1 and 2 weeks. The immature embryos were subcultured on the improved LSD1.5 medium that was supplemented with 10 $\mathrm{mg}^{-1}$ PPT for 3 weeks. Proliferated type I calli were excised to small pieces and cultured on improved LSD1.5 medium that was supplemented with $10 \mathrm{mg}^{-1}$ PPT for 3 weeks. Original LSD1.5 medium that contained $250 \mathrm{mg}^{-1}$ cefotaxime without $\mathrm{AgNO}_{3}$ were also used for comparison. Incubation for callus induction and proliferation were performed at $25^{\circ} \mathrm{C}$ in the dark. Proliferated calli were excised again and cultured on LSZ medium supplemented with $5 \mathrm{mg}^{-1} \mathrm{PPT}$ at $25^{\circ} \mathrm{C}$ under continuous illumination (about $50 \mu \mathrm{mol} \mathrm{m}^{-2}$ $\mathrm{s}^{-1}$ ). Regenerated plants were transferred to $1 / 2 \mathrm{LSF}$ medium, and incubated under the same conditions for 2 weeks. The plants were transferred to soil in pots and grown in a greenhouse. The composition of the media for callus proliferation, regeneration and rooting were that previously described (Ishida et al., 1996).

\section{Assay for GUS activity}

Expression of GUS in T0 and T1 plants was examined by a calorimetric assay using substance 5 bromo-4-chloro-3-indolyl $\beta$ - $D$-glucuronide $(\mathrm{X}$ Gluc) described by Hiei et al. (1994).

\section{Test of progeny for resistance to herbicide}

For evaluation of PPT resistance, $0.2 \%$ Basta (Hoechst, Frankfurt, Germany) solution was sprayed on leaves of the $\mathrm{T} 1$ seedlings 10 days after sowing. Resistance to the herbicide was scored 4 days after spraying.

\section{Isolation DNA and Southern hybridization}

DNA was extracted from the leaf tissues of T0 plants by the procedure described by Komari et al. (1989). Ten $\mu \mathrm{g}$ of DNA was digested with PstI and fractionated on a $0.7 \%$ agarose gel by electrophoresis at $1.5 \mathrm{~V} \mathrm{~cm}^{-1}$ for $15 \mathrm{~h}$. Southern hybridization was carried out according to Sambrook et al. (1989). The probes for gus was previously de- scribed (Ishida et al., 1996).

\section{Results and Discussion}

Screening of additives to media that stimulated callus induction from immature embryos of maize

Inbreds $\mathrm{H} 99$ and A188 respond similarly well to tissue culture in general but responded quite differently to infection with $A$. tumefaciens (Table 1), when callus induction from the immature embryos of these inbreds that were pre-cultured with or without $A$. tumefaciens was examined using callus induction media that contained no selective agents for transformants. Type I calli were induced at high frequencies from the non-inoculated embryos in both genotypes and from the inoculated embryos of A188. Induction of type I callus from the inoculated embryos of $\mathrm{H} 99$ was severely reduced and "slimy" cells were produced (Fig. 1A), indicating that bacteria inhibited proliferation of the cells of H99. It is possible that this inhibition is a blocking hurdle in the transformation of H99. Therefore, tissue culture conditions, especially additives to the media, that can alleviate the inhibition were extensively examined.

\section{Inhibitors of biosynthesis or activity of ethylene}

The effect of inhibitors of biosynthesis or the action of ethylene on tissue cultures of maize have been studied extensively, and a number of studies reported that $\mathrm{AgNO}_{3}$, which is an inhibitor of the action of ethylene, improved callus induction (Vain et al., 1989; Songstad et al., 1991). Therefore, $\mathrm{AgNO}_{3}$ was tested first. A significant increase in the frequency of type I calli from the inoculated immature embryos in $\mathrm{H} 99$ occurred, and this effect was observed in a range of concentration of $\mathrm{AgNO}_{3}$ of 5 $\mu \mathrm{M}$ to $100 \mu \mathrm{M}$ (Table 1, Fig. 1B). Secondly, aminoethoxyvinylglycine (AVG) and aminoxyacetic acid (AOA), which are known as inhibitors of ethylene biosynthesis, were examined. AVG and AOA did not much improve the callus induction from the inoculated immature embryos in H99 (Table 1). AVG slightly stimulated the callus induction, but the effect varied from experiment to experiment.

An increase in ethylene production in plant tissues inoculated with $A$. tumefaciens was observed in carrot (Canfield and Moore, 1983) and melon (Ezura et al., 2000). A reduction in the damage by infection of $A$. tumefaciens by $\mathrm{AgNO}_{3}$ (EnriquezObregón et al., 1999), an increase in the transient expression of a transgene by AVG (Ezura et al., 2000 ), and an increase in the efficiency of transformation by introduction of an antisense gene for a 
gene involved in ethylene biosynthesis (Gapper et al., 2002) and by the addition of $\mathrm{AgNO}_{3}$ to the medium (De Block, 1988; Zhao et al., 2001) were also reported. In contrast, several reports indicated that the addition of $\mathrm{AgNO}_{3}$ did not increase the efficiency of transformation (Metz et al., 1995;

Table 1 Effects of antibiotics and additives for callus induction on immature embryos

\begin{tabular}{|c|c|c|c|c|c|}
\hline \multirow{2}{*}{ Variety } & \multirow{2}{*}{ Inoculation } & \multirow{2}{*}{ Antibiotics } & \multicolumn{2}{|c|}{ Additives } & \multirow{2}{*}{ Callus induction } \\
\hline & & & Name & conc. $(\mu \mathrm{M})$ & \\
\hline \multirow[t]{27}{*}{ H99 } & + & cefo. & - & - & Low \\
\hline & & & SOD & 200 & Low \\
\hline & & & Catalase & 100 & Low \\
\hline & & & SOD + Catalase & $200+100$ & Low \\
\hline & & & $\mathrm{AgNO}_{3}$ & 5 & Medium \\
\hline & & & & 10 & Medium \\
\hline & & & & 50 & Medium \\
\hline & & & & 100 & Medium \\
\hline & & & $A V G$ & 0.5 & Low - Medium \\
\hline & & & & 1 & Low - Medium \\
\hline & & & & 3 & Low \\
\hline & & & $\mathrm{AOA}$ & 0.5 & Low \\
\hline & & & & 1 & Low \\
\hline & & & & 3 & Low \\
\hline & & & $\mathrm{CoCl}_{2} \cdot 6 \mathrm{H}_{2} \mathrm{O}$ & 10 & Low \\
\hline & & & $\mathrm{NiCl}_{2} \cdot 6 \mathrm{H}_{2} \mathrm{O}$ & 10 & Low \\
\hline & & & $\mathrm{CuSO}_{4} \cdot 5 \mathrm{H}_{2} \mathrm{O}$ & 1 & Low - Medium \\
\hline & & & & 10 & Low - Medium \\
\hline & & & & 50 & Low \\
\hline & & & & 100 & Low \\
\hline & & carb. & - & - & Medium \\
\hline & & & $\mathrm{AgNO}_{3}$ & 10 & High \\
\hline & & & STS & 5 & High \\
\hline & & & & 10 & High \\
\hline & & & & 30 & High \\
\hline & - & cefo. & - & - & High \\
\hline & & carb. & $\mathrm{AgNO}_{3}$ & 10 & High \\
\hline \multirow[t]{4}{*}{ W182E } & + & cefo. & - & - & Low \\
\hline & & & $\mathrm{AgNO}_{3}$ & 10 & Medium \\
\hline & & carb. & - & - & Medium \\
\hline & & & $\mathrm{AgNO}_{3}$ & 10 & High \\
\hline \multirow[t]{6}{*}{ A188 } & + & cefo. & - & - & High \\
\hline & & & $\mathrm{AgNO}_{3}$ & 10 & High \\
\hline & & carb. & - & - & High \\
\hline & & & $\mathrm{AgNO}_{3}$ & 10 & High \\
\hline & - & cefo. & - & - & High \\
\hline & & carb. & $\mathrm{AgNO}_{3}$ & 10 & High \\
\hline
\end{tabular}

Inoculation of Agrobacteirum, +: immature embryos were inoculated with Agrobacterium tumefaciens LBA4404 (pSB131) at $1 \times 10^{9} \mathrm{cfu} \mathrm{ml}^{-1}$; - : immature embryos were treated with a mock inoculation without Agrobacterium.

Antibiotics, cefo, cefotaxime; carb., carbenicillin; each antibiotic was added to the medium at a concentration of $250 \mathrm{mg}^{-1}$.

Additives, unit of concentration of SOD and catalase was $\mathrm{mg} \mathrm{l}^{-1}$.

Callus induction, High, more than $60 \%$ of immature embryos induced calli; Medium, callus induction was observed 20 to $60 \%$ of immature embryos; Low, less than $20 \%$ of immature embryos induced calli. Inoculated immature embryos were cultivated on each medium for 2 weeks, and then callus induction was investigated. 

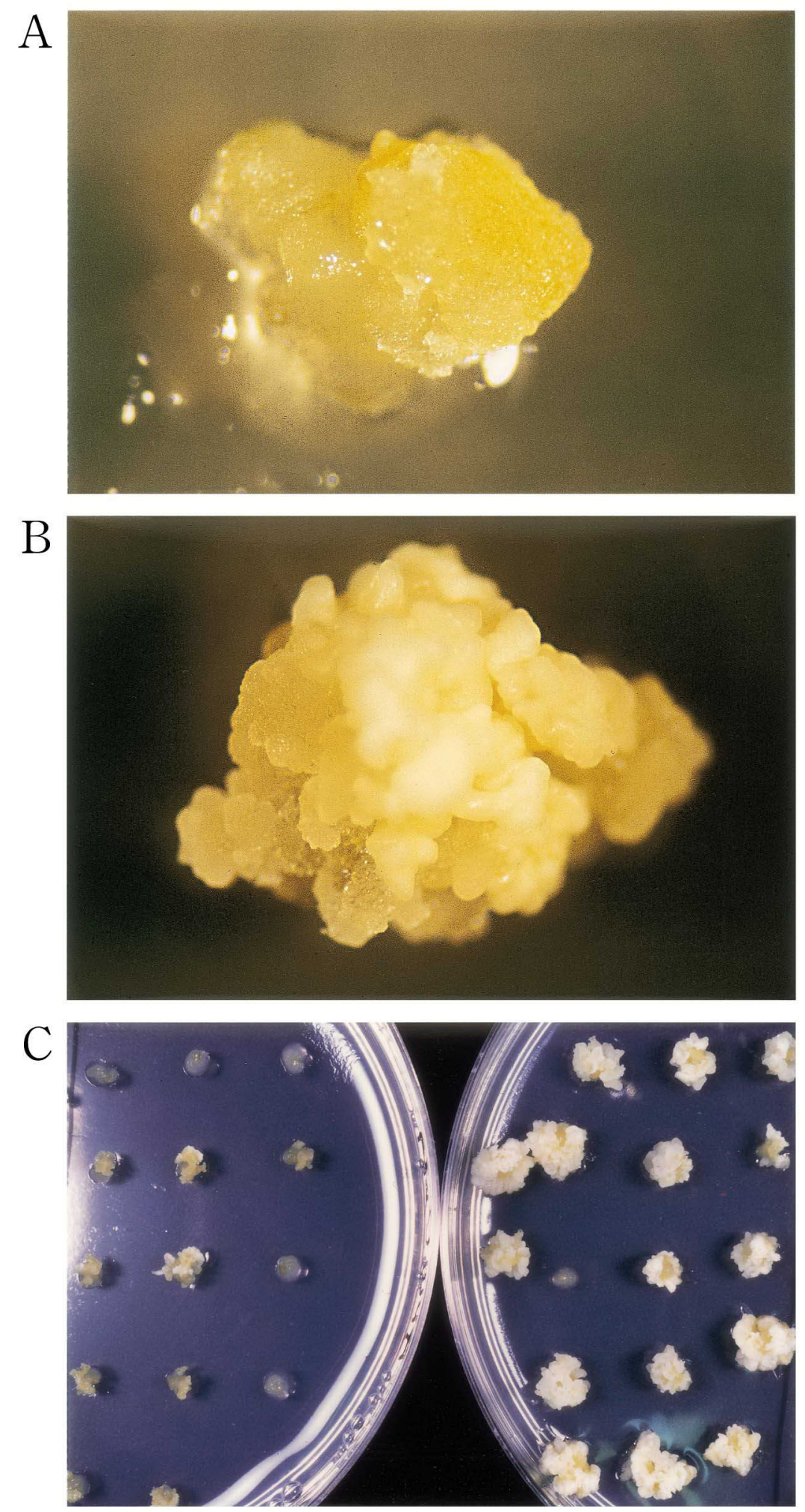

Fig. 1 Response of immature embryos of H99 infected with A. tumefaciens LBA4404(pSB131). (A) Immature embryo that was cultured on the "original medium" (250 $\mathrm{mgl}^{-1}$ cefotaxime without $\mathrm{AgNO}_{3}$ ) for 2 weeks. (B) Immature embryo that was cultured on $\mathrm{AgNO}_{3}$-containing medium (250 $\mathrm{mgl}^{-1}$ cefotaxime and 10 $\mu \mathrm{M} \mathrm{AgNO}$ ) for 2 weeks. (C) Immature embryos that were cultured on the "original medium" (left) and on the "improved medium" (250 $\mathrm{mgl}^{-1}$ carbenicillin and $10 \mu \mathrm{M} \mathrm{AgNO}$ ) (right) for 4 weeks. 
Gapper et al, 2002). The results presented here indicate that ethylene may be involved in the inhibition of callus induction from immature embryos of $\mathrm{H} 99$ by bacteria but did not provide any conclusive evidence.

\section{Other metal ions}

Roustan et al. (1989) reported that stimulation of somatic embryogenesis in suspension-cultured cells of carrot occurred on the addition of $\mathrm{CoCl}_{2}$ or $\mathrm{NiCl}_{2}$. Increase in the frequency of plant regeneration from immature embryos of indica rice by addition of $\mathrm{CuSO}_{4}$ was also reported (Sahrawat and Chand, 1999). These salts were then tested. $\mathrm{CoCl}_{2}$ and $\mathrm{NiCl}_{2}$ did not improve the callus induction from the inoculated immature embryos in $\mathrm{H} 99$, but $\mathrm{CuSO}_{4}$ slightly increased the callus induction at concentrations of $1 \mu \mathrm{M}$ to $10 \mu \mathrm{M}$, which were 10 to 100 fold higher than the typical concentration of $\mathrm{CuSO}_{4}$ in plant tissue culture (Table 1).

\section{Antioxidants}

It is well-known that hydrogen peroxide tends to damage cells in tissue culture in many plant species, and various trials, including the addition of antioxidants to the media, have been carried out to reduce the damage. Ishii (1988) showed that superoxide dismutase (SOD) and catalase increased callus formation from rice protoplasts. In the present study, however, SOD and catalase were examined as mentioned above but did not show any positive effects (Table 1). Although the effect of other antioxidants for reduction of the damage caused by inoculation of $A$. tumefaciens was demonstrated in grape (Perl et al., 1996) and rice (EnríquezObregón et al., 1999), no further investigation was done in the present study.

\section{Antibiotics}

Antibiotics, which are added to the media for elimination of bacteria from plant tissues, are almost always present in the media after co-cultivation in Agrobacterium-mediated transformation. Cefotaxime, which is an antibiotic for gram-negative bacteria, has been widely used for this purpose, and our original transformation protocol for maize (Ishida et al., 1996) employed this antibiotic as well. Although inhibition of shoot regeneration and/or callus formation by cefotaxime was observed in Brassica (De Block et al,, 1989), rose (Orlikowska et al., 1996) and turnip (Kuvshinov et al., 1999), it was not an issue for A188 because calli were induced from the immature embryos of A188 on a cefotaxime-containing medium at a high frequency with or without inoculation with $A$, tume- faciens (Table 1). Zhao et al. (2001), however, observed the inhibition of callus formation from immature embryos of maize hybrid $\mathrm{Hi}$ II and an increase in the efficiency of transformation with the use of carbenicillin instead of cefotaxime.

H99 and A188 responded to antibiotics quite differently in this study. Immature embryos of H99 without inoculation of $A$. tumefaciens showed callus induction on the cefotaxime-containing medium at a high frequency, but a few immature embryos of H99 produced type I calli on the cefotaxime-containing medium after co-cultivation with $A$. tumefaciens (Table 1). Thus, cefotaxime exhibited a negative impact on infected immature embryos only in H99. In contrast, about half of the inoculated immature embryos of $\mathrm{H} 99$ produced type I calli on the medium that contained carbenicillin instead of cefotaxime (Table 1). There was no difference between cefotaxime- and carbenicillin-containing media in the frequencies of callus induction from inoculated immature embryos of A188, but proliferation of the calli on the carbenicillin-containing medium appeared more vigorous than that on the cefotaxime-containing medium (data not shown). These results indicate that the presence of cefotaxime might be a negative factor in the failure of transformation of varieties including $\mathrm{H} 99$ (Ishida $e t$ al., 1996).

\section{Combination of carbenicillin and silver ion}

Immature embryos of $\mathrm{H} 99$ inoculated with $A$. tumefaciens induced type I calli on the medium that contained both $\mathrm{AgNO}_{3}$ and carbenicillin at a frequency even higher than on media that contained either one of them separately (Table 1, Fig. 1C). Silver thiosulfate, which is used in plant tissue culture as an inhibitor of the activity of ethylene action similarly to $\mathrm{AgNO}_{3}$, also affected positively the callus induction from the infected embryos of H99 at a concentration of 5-30 $\mu \mathrm{M}$ (Table 1).

\section{Callus induction in another genotype, W182E}

Callus induction from the infected immature embryos of W182E was examined under a subset of experimental conditions described above for $\mathrm{H} 99$ (Table 1). The responses of the immature embryos of W182E were essentially identical to those of $\mathrm{H} 99$ under these conditions; $\mathrm{AgNO}_{3}$ and carbenicillin showed positive effects separately, whereas cefotaxime showed a negative effect, and a combination $\mathrm{AgNO}_{3}$ and carbenicillin further improved callus induction. It is possible, therefore, that a combination of $\mathrm{AgNO}_{3}$ and carbenicillin will be useful in callus induction from immature embryos inoculated with $A$. tumefaciens in various genotypes of maize. 
Transformation of $H 99$ and W117 by an improved protocol

The composition of the media that had been the most suitable for callus induction from the infected immature embryos of $\mathrm{H} 99$ was tested in the production of transgenic maize plants. In each experiment, between 20 and 80 immature embryos of $\mathrm{H} 99$ were co-cultivated with LBA4404 (pSB131) and then cultured either on the LSD1.5 medium that contained phosphinothricin (PPT) and cefotaxime, which was referred to as the "original medium", or on the LSD1.5 medium that contained PPT, carbenicillin and $\mathrm{AgNO}_{3}$, which was referred to as the "improved medium", for 8 weeks. Further handling was performed according to the original protocol (Ishida et al., 1996).

Proliferation of transformed cells was observed in all of 9 independent experiments employing the "improved medium". These cells were eventually plated on the regeneration medium that contained PPT, and plants were regenerated from most of the PPT-resistant calli. The majority of regenerated plants showed expression of the GUS and were normal in morphology and fertile. The frequency of transformation varied and the average was $2.8 \%$ (13 independent GUS-positive plants per 466 inoculated immature embryos). The highest frequency in an experiment was $15 \%$ (Table 2). On the other hand, cells did not proliferate on the "original medium", and no transformed plants were obtained in these experiments, which was consistent with the results previously reported (Ishida et al., 1996).

Immature embryos of W117 were also inoculated with LBA4404 (pSB131) and selected on the "improved" and "original media". Although no regenerated plant was obtained from immature embryos selected on the "original medium", two independent plants were regenerated from calli selected on the "improved medium", and one of them showed expression of the GUS gene (Table 2).

Southern analysis was carried out to confirm the presence of the foreign genes in the transformed plants of H99. Extracted DNAs from 12 indepen-

Table 2 Summary of transformation using original or improved selection medium

\begin{tabular}{|c|c|c|c|c|c|c|}
\hline \multirow[b]{2}{*}{ Variety } & \multirow[b]{2}{*}{$\begin{array}{l}\text { Selection } \\
\text { medium }\end{array}$} & \multirow[b]{2}{*}{$\begin{array}{c}\text { Experiment } \\
\text { no. }\end{array}$} & \multicolumn{3}{|c|}{ Number of immature embryos } & \multirow[b]{2}{*}{$\begin{array}{c}\text { Frequency } \\
(\mathrm{B} / \mathrm{A}, \%)\end{array}$} \\
\hline & & & $\begin{array}{l}\text { Inoculated } \\
\text { (A) }\end{array}$ & $\begin{array}{c}\text { Produced } \\
\text { antibiotic- } \\
\text { resistant plants }\end{array}$ & $\begin{array}{c}\text { Produced } \\
\text { antibiotic- resistant, } \\
\text { GUS+plants (B) }\end{array}$ & \\
\hline \multirow[t]{10}{*}{ H99 } & Improved & 1 & 63 & 1 & 1 & 1.6 \\
\hline & & 2 & 41 & 3 & 1 & 2.4 \\
\hline & & 3 & 59 & 3 & 2 & 3.4 \\
\hline & & 4 & 20 & 3 & 3 & 15.0 \\
\hline & & 5 & 50 & 1 & 1 & 2.0 \\
\hline & & 6 & 50 & 2 & 1 & 2.0 \\
\hline & & 7 & 50 & 2 & 1 & 2.0 \\
\hline & & 8 & 54 & 2 & 1 & 1.9 \\
\hline & & 9 & 79 & 2 & 2 & 2.5 \\
\hline & Original & $1-9$ & 655 & 0 & 0 & 0 \\
\hline \multirow[t]{2}{*}{ W117 } & Improved & 1 & 71 & 2 & 1 & 1.4 \\
\hline & Original & 1 & 60 & 0 & 0 & 0 \\
\hline \multirow[t]{4}{*}{ A188 } & Improved & 1 & 21 & 10 & 6 & 28.6 \\
\hline & & 2 & 24 & 16 & 8 & 33.3 \\
\hline & & 3 & 47 & 28 & 23 & 48.9 \\
\hline & Original & $1-3$ & 224 & 56 & 34 & 15.2 \\
\hline
\end{tabular}

Infected immature embryos were cultured on selection medium supplemented with PPT for 7-8 weeks. Transgenic plants were produced on regeneration medium supplemented with PPT. Details were described in Materials and Methods.

${ }^{11}$ Improved selection medium: Original LSD1.5 medium (Ishida et al., 1996) without cefotaxime, plus $250 \mathrm{mg}^{-1}$ carbenicillin and $10 \mu \mathrm{M} \mathrm{AgNO}$.

${ }^{2}$ Numbers of immature embryos in experiments using original selection medium are shown as the sum of the results of 9 experiments (H99) and 3 experiments (A188), respectively. 
dent transformation events were digested with PstI and hybridized with the GUS probe. All events showed different patterns of hybridization, demonstrating random integration of the transgenes into

$$
\begin{array}{lllllllllllll}
\text { C } & 1 & 2 & 3 & 4 & 5 & 6 & 7 & 8 & 9 & 10 & 11 & 12
\end{array}
$$

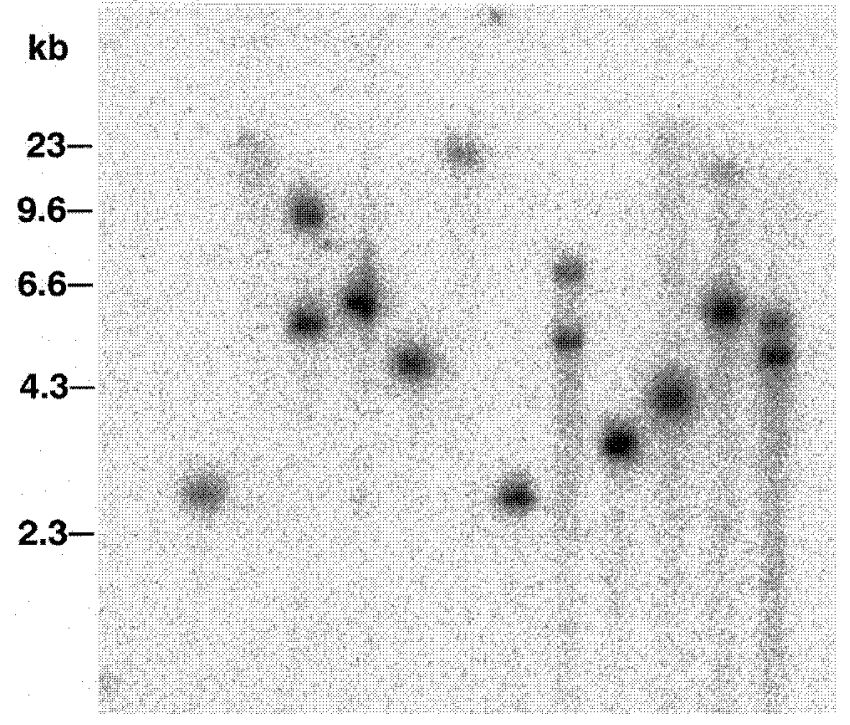

Fig. 2 Southern blot analysis of transformed plants of H99 (T0 generation). DNA extracted from PPTresistant and GUS-positive plants was digested with Pst1 and allowed to hybridize to the gus probe. Lane $\mathrm{C}$, non-transformed control plant; lanes $1-12$, transformed plants. the plant chromosomes (Fig. 2). Eight out of 12 events had a single copy of the GUS gene and copy numbers of the transgene in the other events were 2.

Progeny of H99 transformed with LBA4404 (pSB131) were obtained by self-pollination or cross-pollination with non-transformed H99. Expression of both the bar and GUS genes was investigated. A solution of herbicide Basta was sprayed on the seedlings for investigation of PPT resistance. PPT - sensitive plants became dwarfed 4 days after spraying and completely died within 2 weeks. In contrast, PPT-resistant plants did not show any damage caused by the herbicide and grew normally. The PPT resistance and GUS expression were strongly linked, and clear Mendelian segregation was observed for both traits. All progeny obtained by self-pollination from 3 events showed segregation ratios of $3: 1$ for both traits (resistant : sensitive and positive : negative). Eight events out of 10 events obtained by cross-pollination with nontransformed H99 showed segregation ratios of 1:1. Event No. 33 showed a strange segregation ratio of 1:2. Event No. 51, following cross-pollination with non-transformed H99, showed a segregation ratio of $3: 1$, indicating that the transgenes were inserted into 2 loci (Table 3).

Therefore, the integration, expression and inheritance of the transgenes were clearly demonstrated

Table 3 Genetic analysis of independent transformants of H99 produced by LBA4404 (pSB131)

\begin{tabular}{|c|c|c|c|c|c|c|c|c|c|}
\hline \multirow{3}{*}{$\begin{array}{c}\text { Transformant } \\
\text { (T0) }\end{array}$} & \multirow{3}{*}{ Cross ${ }^{11}$} & \multicolumn{3}{|c|}{ Herbicide resistance } & \multirow{3}{*}{$\chi^{2}$} & \multicolumn{3}{|c|}{ GUS expression } & \multirow{3}{*}{$\chi^{2}$} \\
\hline & & \multicolumn{2}{|c|}{$\begin{array}{c}\text { Number of plants in } \\
\text { T1 generation }\end{array}$} & \multirow{2}{*}{$\begin{array}{c}\text { Ratio } \\
\text { R:S }\end{array}$} & & \multicolumn{2}{|c|}{$\begin{array}{c}\text { Number of plants in } \\
\text { T1 generation }\end{array}$} & \multirow{2}{*}{$\begin{array}{l}\text { Ratio } \\
+:-\end{array}$} & \\
\hline & & $\mathrm{R}$ & $\mathrm{S}$ & & & + & - & & \\
\hline 41 & self & 27 & 5 & $3: 1$ & 1.50 & 27 & 5 & $3: 1$ & 1.50 \\
\hline \multirow[t]{2}{*}{32} & self & 26 & 6 & $3: 1$ & 0.67 & 26 & 6 & $3: 1$ & 0.67 \\
\hline & female & 18 & 15 & $1: 1$ & 0.27 & 18 & 15 & $1: 1$ & 0.27 \\
\hline \multirow[t]{2}{*}{54} & self & 23 & 9 & $3: 1$ & 0.17 & 23 & 9 & $3: 1$ & 0.17 \\
\hline & female & 13 & 19 & $1: 1$ & 1.13 & 13 & 19 & $1: 1$ & 1.13 \\
\hline 10 & female & 15 & 10 & $1: 1$ & 1.00 & 15 & 10 & $1: 1$ & 1.00 \\
\hline 11 & female & 19 & 13 & $1: 1$ & 1.13 & 19 & 13 & $1: 1$ & 1.13 \\
\hline 20 & female & 18 & 14 & $1: 1$ & 0.50 & 18 & 14 & $1: 1$ & 0.50 \\
\hline 21 & female & 3 & 6 & $1: 1$ & 1.00 & 3 & 6 & $1: 1$ & 1.00 \\
\hline 31 & female & 16 & 16 & $1: 1$ & 0.00 & 14 & 18 & $1: 1$ & 0.50 \\
\hline 33 & female & 10 & 21 & & & 10 & 21 & & \\
\hline 51 & female & 20 & 10 & $3: 1$ & 1.04 & 21 & 9 & $3: 1$ & 0.40 \\
\hline 55 & female & 16 & 16 & $1: 1$ & 0.00 & 16 & 16 & $1: 1$ & 0.00 \\
\hline Control (H99) & & 0 & 32 & & & 0 & 32 & & \\
\hline
\end{tabular}

$\mathrm{R}$, resistant; $\mathrm{S}$, sensitive.

Ratios that give the smallest $\chi^{2}$ values are shown together with the $\chi^{2}$ values.

${ }^{1)}$ self, T1 plants were obtained by self pollination; female, T1 plants were obtained by crossing with pollen of non

- transformed H99. 
for the transgenic plants regenerated from immature embryos of $\mathrm{H} 99$ that were co-cultivated with $A$. tumefaciens by Southern hybridization and genetic analysis. Public inbred line $\mathrm{H} 99$ belongs to the "Lancaster Sure Crop Group" and is distantly related to A188 of the "Iowa Stiff Stalk Synthetic Group". W117 and W182 are public inbreds in another class, the "Miscellaneous Group". This is the first report of transformation mediated by Agrobacterium of public inbred lines other than genotype A188. Furthermore, the fact that the improved media enhanced the callus induction and/or transformation in diverse genotypes suggests that the improved protocol will be useful for a broad range of varieties of maize.

\section{Transformation of $A 188$ by the improved protocol}

The improved protocol was tested in A188 using immature embryos in two different development stages. First, like all the experiments described above, immature embryos of 1.0 to $1.2 \mathrm{~mm}$ in length, which were in the stage most suitable for Agrobacterium-mediated transformation (Ishida et al., 1996), were inoculated with LBA4404 (pSB131) and cultured on the improved or original media that contained PPT. The average frequency of transformation in 3 experiments using the improved medium was $40.2 \%$ and the highest was $48.9 \%$ (Table 2). In contrast, the average frequency of transformation by the original protocol was $15.2 \%$, which was similar to the results in the previous report (Ishida et al., 1996). Therefore, the efficiency of transformation was much higher with the improved protocol than that with the original protocol even in A188.

Immature embryos of A188 of 1.5 to $2.0 \mathrm{~mm}$ in length, which were in a stage not good for transformation by the original protocol, were then examined as above. Type I calli appearing quite vigorous were induced from the infected immature embryos cultured on the improved media only. PPT-resistant and GUS-positive plants were regenerated from 13 immature embryos out of 47 inoculated immature embryos, and the frequency of transformation was $27.7 \%$ in the improved protocol. No transformed plants were regenerated from the infected immature embryos of 1.5 to $2.0 \mathrm{~mm}$ in the original protocol as reported by Ishida et al. (1996). One of the problems with the original protocol was the very narrow windows for optimal ranges in various experimental factors, which included the developmental stages of immature embryos.

The improvement in the efficiency of transformation in A188 by the new protocol was not well anticipated from the results of the callus induction assays, because the new media composition did not affect positively the immature embryos of A188, and the new protocol was primarily designed to alleviate the damage to immature embryos of H99 by infection. These data suggest that certain damage was "hidden" even in the transformation of A188 and that the new protocol was able to alleviate such silent damage.

\section{Conclusions}

An improved protocol for maize transformation was developed in the present study. In this protocol, public inbreds $\mathrm{H} 99$ and W117 were transformed efficiently for the first time, and another public inbred A188 was transformed more efficiently than with the original protocol. The new protocol and further improvements will certainly contribute to higher frequencies of transformation, to transformation of a broader range of genotypes, and to wider windows of various experimental factors in maize, in which transformation mediated by $A$. tumefaciens is becoming a standard technique in molecular biology and biotechnology.

The present study has implied the importance of two approaches for improvement of transformation protocols; optimization of factors using 1) the most suitable and responsive genotypes or materials and 2) difficult and less responsive genotypes or materials. The use of A188 was one of the most important factors in the development of the original protocol, but information on further improvement had not been obtained from the use of A188 for some time. The present study then identified improved conditions for H99, and such conditions also further optimized the transformation of A188.

\section{Acknowledgements}

The authors thank Drs. T. Kubo and T. Kumashiro for helpful discussions and advice. The technical assistance of Ms E. Usami and M. Noguchi is gratefully acknowledged.

\section{References}

Brettschneider, R., Becker, D., Lorz, H., 1997. Efficient transformation of scutellar tissues of immature maize embryos. Theor. Appl. Genet, 94: 737-748.

Canfield, M. L., Moore, L. W., 1983. Production of ethylene by Daucus carota inoculated with Agrobacterium tumefaciens and Agrobacterium rhizogenes, Z. Pflanzenphysiol., 112: 471- 474 .

Cheng, M., Fry, J. E., Pang, S., Zhou, H., Hironaka, C. M., Duncan, D. R., Conner, T. W., Wan, Y., 1997. Genetic transformation of wheat mediated by Agrobacterium tumefaciens. Plant Physiol., 115: 971-980. 
De Block, M., 1988. Genotype-independent leaf disk transformation of potato (Solanum tuberosum) using Agrobacterium tumefaciens. Theor. Appl. Genet, 76: $767^{-}$ 774.

De Block, M., Brouwer, D. D., Tenning, P., 1989. Transformation of Brassica napus and Brassica oleracea using Agrobacterium tumefaciens and the expression of the bar and neo genes in the transgenic plants. Plant Physiol., 91: 694-701.

Deji, A., Sakakibara, H., Ishida, Y., Yamada, S., Komari, T., Kubo, T., Sugiyama, T., 2000. Genomic organization and transcriptional regulation of maize $Z m R R 1$ and $Z m R R 2$ encoding cytokinin-inducible response regulators. Biochim. Biophys. Acta, 1492: 216-220.

D'Halluin, K., Bonne, E., Bossut, M., De Beuckeleer, M., Leemans, J, 1992. Transgenic maize plants by tissue electroporation. Plant Cell, 4: 1495-1505.

Enríquez-Obregón, G. A., Prieto-Samsónov, D. L., de la Riva, G. A., Pérez, M., Selman-Housein, G., Vázquez Padrón, R. I., 1999. Agrobacterium-mediated Japonica rice transformation: a procedure assisted by an antinecrotic treatment. Plant Cell, Tissue Organ Cult., 59: $159-168$

Ezura, H., Yuhashi, K.-I., Yasuta, T., Minamisawa, K., 2000. Effect of ethylene on Agrobacterium tumefaciens - mediated gene transfer to melon. Plant Breeding, 119: $75-79$

Frame, B. R., Drayton, P. R., Bagnali, S. V., Lewnaw, C. J., Bullock, W. P., Wilson, H. M., Dunwell, J. M., Thompson, J. A., Wang, K., 1994. Production of fertile transgenic maize plants by silicon carbide whiskermediated transformation. Plant J., 6: 941-948.

Frame, B. R., Shou, H., Chikwamba, R. K., Zhang, Z., Xiang, C., Fonger, T. M., Pegg, S. E. K., Li, B., Nettleton, D. S., Pei, D., Wang, K., 2002. Agrobacterium tumefaciens--mediated transformation of maize embryos using a standard binary vector system. Plant Physiol., 129: 13-22,

Fromm, M. E., Morrish, F., Armstrong, C., Williams, R., Thomas, J., Klein, T. M., 1990. Inheritance and expression of chimeric genes in the progeny of transgenic maize plants. Bio/technology, 8: 833-839.

Gapper, N. E., McKenzic, M. J., Christey, M. C., Braun, R. H., Coupe, S. A., Lill, R. E., Jameson, P. E., 2002. Agrobacterium tumefaciens-mediated transformation to alter ethylene and cytokinin biosynthesis in broccoli. Plant Cell, Tissue Organ Cult., 70: 41-50.

Gordon-Kamm, W. J., Spencer, T. M., Mangano, M. L., Adams, T. R., Daines, R. J., Start, W. G., O'Brien, J. V., Chambers, S. A., Adams Jr., W. R., Willetts, N. G., Rice, T. B., Mackey, C. J., Krueger, R. W., Kausch, A. P., Lemaux, P. G., 1990. Transformation of maize cells and regeneration of fertile transgenic plants. Plant Cell, 2: $603-618$.

Gould, J., Devey, M., Hasegawa, O., Ulian, E., Peterson, G., Smith, R. H., 1991. Transformation of Zea mays L. using Agrobacterium tumefaciens and the shoot apex. Plant Physiol., 95: 426-434.

Graves, A. C. F., Goldman, S. L., 1986. The transformation of Zea mays seedlings with Agrobacterium tumefaciens. Plant Mol. Biol., 7: 43-50.

Grimsley, N., Horn, T., Davis, J. W., Horn, B., 1987. Agrobacterium-mediated delivery of infectious maize streak virus into maize plants. Nature, 325: 177-179.

Hiei, Y., Ohta, S., Komari, T., Kumashiro, T., 1994. Efficient transformation of rice (Oryza sativa L.) mediated by Agrobacterium and sequence analysis of the boundaries of the T-DNA. Plant J., 6: 271-282.

Hodges, T. K., Kamo, K. K., Imbrie, C. W., Becwar, M. R., 1986. Genotype specificity of somatic embryogenesis and regeneration in maize. Bio/tecnology, 4: 219-223.

Horsch, R. B., Fry, J. E., Hoffmann, N. L., Eichholtz, D., Rogers, S. G., Fraley, R. T., 1985. A simple and general method for transferring genes into plants. Science, 227: $1229-1231$.

Ishida, Y., Saito, H., Ohta, S., Hiei, Y., Komari, T., Kumashiro, T., 1996. High efficiency transformation of maize (Zea mays L.) mediated by Agrobacterium tumefaciens. Nature Biotechnol., 14: $745-750$.

Ishii, S., 1988. Factors influencing protoplast viability of suspension-cultured rice cells during isolation process. Plant Physiol., 88: 26- 29.

Komari, T., Saito, Y., Nakakido, F., Kumashiro, T., 1989. Efficient selection of somatic hybrids in Nicotiana tabacum L. using a combination of drug resistance markers introduced by transformation. Theor. Appl. Genet, 77: 547-552.

Kuvshinov, V., Koivu, K., Kanerva, A., Pehu, E., 1999 Agrobacterium tumefaciens-mediated transformation of greenhouse - grown Brassica repa ssp. oleifera. Plan Cell Rep., 18: 773- -777.

Metz, T. D., Dixit, R., Earle, E. D., 1995. Agrobacterium tumefaciens-mediated transformation of broccoli (Brassica oleracea var. italica) and cabbage (B. oleracea var. capitata). Plant Cell Rep., 15: 287-292.

Negrotto, D., Jolley, M., Beer, S., Wenck, A. R., Hansen, G., 2000. The use of phosphomannose-isomerase as a selection marker to recover transgenic maize plants (Zea mays L.) via Agrobacterium transformation. Plant Cell Rep., 19: 798-803.

Nester E. W., Kosuge, T., 1981. Plasmids specifying plant hyperplasias. Annu. Rev. Microbiol, 35: $531-565$.

Nomura, M., Sentoku, N., Nishimura, A., Lin, J-H., Honda, C., Taniguchi, M., Ishida, Y., Ohta, S., Komari, T., Miyao-Tokumori, M., Kono-Murakami, Y., Tajima, S., Ku, M. S. B., Matsuoka, M., 2000a. The evolution of C4 plants: acquisition of cis-- regulatory sequences in the promoter of $\mathrm{C} 4$-type pyruvate, orthophosphate dikinase gene. Plant J., 22: 211-221.

Nomura, M., Katayama, K., Nishimura, A., Ishida, Y., Ohta, S., Komari, T., Miyao-Tokutomi, M., Tajima, S., Matsuoka, M., 2000b. The promoter of $r b c S$ in a C3 plant (rice) directs organ-specific, light-- dependent expression in a $\mathrm{C} 4$ plant (maize), but does not confer bundle sheath cell-specific expression. Plant Mol. Biol., 44: 99-106.

Ohta, S., Mita, S., Hattori, T., Nakamura, K., 1990. Construction and expression in tobacco of a b-glucu- 
ronidase (GUS) reporter gene containing an intron within the coding sequence. Plant Cell Physiol., 31: 805 -813 .

Orlikowsksa, T., Kucharska, D., Nowak, E., Rojek, Z., 1996. Influence of silver nitrate on regeneration and transformation of roses. Genet. Pol., 37A: 122-125.

Perl, A., Lotan, O., Abu-Abied M., Holland, D., 1996. Establishment of an Agrobacterium-mediated transformation system for grape (Vitis vinifera L.): The role of antioxidants during grape-Agrobacterium interactions. Nature Biotechnol, 14: 624-628.

Rhodes, C. A., Pierce, D. A., Mettler, I. J., Mascarenhas, D, Detmer, J. J., 1988. Genetically transformed maize plants from protoplasts. Science, 240: 204- 207.

Roustan, J. P., Latche, A., Fallot, J., 1989. Stimulation of Daucus carota somatic embryogenesis by inhibitors of ethylene synthesis: cobalt and nickel. Plant Cell Rep., 8: $182-185$.

Sahrawat A. K., Chand, S., 1999. Stimulatory effect of copper on plant regeneration in indica rice (Oryza sativa L.). J. Plant Physiol., 154: 517-522.

Sambrook, J., Fritsch, E. F., Maniatis, T., 1989. Molecular Cloning: A Laboratory Manual, 2nd ed., Cold Spring Harbor Laboratory Press, Cold Spring Harbor, New York.

Songstad, D. D., Duncan, D. R., Widholm, J. M., 1988. Effect of 1-aminocyclopropane-1-carboxylic acid, silver nitrate, and norbornadiene on plant regeneration from maize callus cultures. Plant Cell Rep., 7: 262-265. Songstad, D. D., Armstrong, C. L.., Petersen, W. L., 1991. $\mathrm{AgNO}_{3}$ increases type II callus production from immature embryos of maize inbred B73 and its derivatives. Plant Cell Rep., 9: 699-702.

Taniguchi, M., Izawa, K., Ku, M. S. B., Lin, J-H., Saito, H., Ishida, Y., Ohta, S., Komari, T., Matsuoka, M., Sugiyama, T., 2000. The promoter for the maize $C_{4}$ pyruvate, orthophosphate dikinase gene directs cell- and tissue ${ }^{-}$specific transcription in transgenic maize plants. Plant Cell Physiol., 41: 42-48.

Tingay, S., McElroy, D., Kalla, R., Fieg, S., Wang, M., Thornton, S., Brettell, R., 1997. Agrobacterium tumefaciens-mediated barley transformation. Plant J., 11: $1369-1376$.

Vain, P., Yean, H., Flament, P., 1989. Enhancement of production and regeneration of embryogenic type II callus in Zea mays L. by $\mathrm{AgNO}_{3}$. Plant Cell, Tissues Organ Cult., 18: 143-151.

Zhao, Z.-Y., Cai, T., Tagliani, L., Miller, M., Wang, N., Peng, H., Rudert, M., Schoeder, S., Hondred, D., Seltzer, J., Pierce, D., 2000. Agrobacterium--mediated sorghum transformation. Plant Mol. Biol., 44: 789-798.

Zhao, Z.--Y., Gu, W., Cai, T., Tagliani, L., Hondred, D., Bond, D., Schroeder, S., Rudert, M., Pierce, D., 2001. High throughput genetic transformation mediated by Agrobacterium tumefaciens in maize. Mol. Breed., 8: $323-333$. 